\title{
RESPONSABILIDADE SOCIAL CORPORATIVA E O DESEMPENHO FINANCEIRO NO SETOR DE ENERGIA ELÉTRICA: UM ESTUDO COM MODELO DE DADOS EM PAINÉIS \\ CORPORATE SOCIAL RESPONSIBILITY AND FINANCIAL PERFORMANCE IN THE ELECTRICAL ENERGY SECTOR: A STUDY WITH PANEL DATA MODEL
}

\section{Flávio Ribeiro}

Doutorando e mestre em Contabilidade pela Universidade Federal do Paraná, professor assistente do Departamento de Ciências Contábeis da Universidade Estadual do

Centro-Oeste, Irati (PR), Brasil

\section{Thays Aparecida Alves}

Graduada em Ciências Contábeis pela Universidade Estadual do Centro-Oeste, Irati (PR), Brasil

\section{Marines Taffarel}

Doutora em Administração pela Pontifícia Universidade Católica do Paraná, mestre em Contabilidade pela Universidade Federal do Paraná, professora adjunta do Departamento de Ciências Contábeis da Universidade Estadual do Centro-Oeste, Irati (PR), Brasil

\section{Gelson Menon}

Professor do Departamento de Ciências Contábeis da Universidade Estadual do

Centro-Oeste, Irati (PR), Brasil

\section{RESUMO}

A responsabilidade social corporativa (RSC) se tornou de grande importância para as empresas, temática que tem sido um campo fecundo para divergências em relação ao que vem a ser e se é adequado o aporte de recursos para o desenvolvimento de ações na área socioambiental. O objetivo desta pesquisa consistiu em analisar a relação entre os indicadores socioambientais e o desempenho financeiro em companhias abertas do setor de energia elétrica que compõe o Índice Bovespa, no período de 2009 a 2015. Os resultados denotam que tanto o retorno sobre o ativo (ROA) como o retorno sobre o patrimônio líquido (ROE) apresentam resultados similares quando comparados aos investimentos socioambientais e ao tamanho das empresas. Nota-se principalmente que os indicadores sociais internos apresentam uma relação direta e significativa com os resultados organizacionais, indicando que investir nos funcionários tende a produzir resultados financeiros positivos para as empresas.

Palavras-chave: Responsabilidade socioambiental; setor de energia elétrica; indicadores sociais.

\section{ABSTRACT}

Corporate social responsibility (CSR) has become of great importance for companies, a theme that has been a fruitful field for divergences in relation to what is and if it is appropriate the contribution of resources for the development of actions in the socioenvironmental area. The objective of this study was to analyze the relationship between socio-environmental indicators and financial performance in public companies of the electric energy sector that makes up the Bovespa Index, from 2009 to 2015. The results show that both, the return on assets (ROA) and the return on equity (ROE), present similar results when compared to socio-environmental investments and the size of companies. It is important to note that internal social indicators show a direct and significant relationship with organizational results, indicating that investing in employees tends to produce positive financial results for companies.

Keywords: Socio-environmental responsibility; electrical energy sector; social indicators.

Endereço dos autores:

Flávio Ribeiro Thays Aparecida Alves

flavioribeiro@unicentro.br_thays.perfil@hotmail.com

Marines Taffarel

marinestaffarel@yahoo.com.br

Gelson Menon

gelsonmenon@gmail.com 


\section{INTRODUÇÃO}

Os serviços de utilidade pública, como o de fornecimento de energia elétrica, são fundamentais para o desenvolvimento econômico, financeiro e social dos países. O setor energético brasileiro se destaca internacionalmente, representando cerca de $2 \%$ da energia elétrica gerada mundialmente (BRASIL, 2015). A capacidade total instalada para a geração de energia no país atingiu o montante de 133,9 GigaWatt (GW), sendo que o potencial de geração hidráulica é de 89,2 GW e representa $67 \%$ do total da energia elétrica consumida no país (BRASIL, 2015).

Por atuarem em um ambiente altamente competitivo e de forte impacto econômico, ambiental e social, as empresas de energia elétrica desempenham papel fundamental nos fatores de responsabilidade socioambiental, tendo em vista que ao longo das últimas décadas o desenvolvimento sustentável vem recebendo atenção de entidades públicas e privadas como mecanismo de promoção do bem-estar social que permita a continuidade e manutenção dos recursos naturais para as gerações futuras (CALIXTO, 2007).

Pesquisas que relacionam investimentos socioambientais e desempenho financeiro têm sido destacadas na academia (MOORE, 2001; PRESTON; O'BANNON, 1997) e, apesar de alguns estudos mostrarem relação positiva entre as variáveis (ALBERTON; COSTA JUNIOR, 2007; KLASSEN; MCLAUGHLIN, 1996; PRESTON; O'BANNON, 1997; ROSSI JÚNIOR, 2009), os resultados não se mostram completos. Assim, questionamentos de que investimentos em ações socioambientais refletem em melhor desempenho financeiro permanecem inconclusivos (CAVALCANTI; BOENTE, 2012; PERRINI et al. 2011) e geram divergências no meio acadêmico, além de debates e preocupações no ambiente corporativo. Para Borba (2006), Crisóstomo, Freire e Vasconcellos (2011) e Holanda et al. (2011), os investimentos socioambientais não exercem influência no desempenho financeiro das empresas. No entanto, Cochran e Wood (1984), Lima et al. (2013), Machado e Machado (2009), Machado, Machado e Santos (2010), Mahoney e Roberts (2007) e Nelling e Webb (2009) apresentam evidências de que empresas com maior responsabilidade social tendem a apresentar melhores resultados financeiros.

Embora existam dúvidas sobre a efetividade da responsabilidade socioambiental, esta se mostra cada vez mais importante no mundo corporativo. Nesse cenário, os desafios da globalização têm reacendido a relevância dos investimentos em fatores sociais e ambientais, tendo em vista que o exercício da responsabilidade social incorpora na cultura empresarial a busca pelo bem-estar social vinculado ao crescimento organizacional.

A prática da responsabilidade social e sua evidenciação proporcionam retornos institucionais e a valorização da imagem empresarial, o que, por consequência, geram benefícios tanto para a empresa como para a sociedade. A responsabilidade social se baseia na proposta de equilíbrio entre fatores sociais, econômicos e ambientais, tornando-se assunto frequente em fóruns nacionais e internacionais, especialmente no meio empresarial (SILVA, 2008).

Diversas pesquisas foram realizadas buscando vincular a responsabilidade socioambiental ao desempenho financeiro das empresas. Brito (2005) destaca que, após efetuar uma compilação entre o desempenho ambiental e o financeiro, constatou que os resultados não eram conclusivos, encontrando correlações positivas, neutras e negativas, de acordo com contexto, amostra e metodologia utilizada. Alguns autores afirmam que as motivações econômico-financeiras para a incorporação da sustentabilidade nas atividades das organizações dependem do contexto da firma, do setor e, especialmente, do país (STEGER, 2004; WAJNBERG, 2008). Nesta pesquisa, busca-se analisar a relação entre os indicadores socioambientais 
e o desempenho financeiro de empresas que compõem o setor de energia elétrica brasileiro e participaram do Índice Bovespa no período de 2009 a 2015.

Perceptivelmente, a literatura sobre a relação entre os investimentos socioambientais e o desempenho financeiro é heterogênea e divergente. Assim, este estudo auxilia no preenchimento de lacunas relacionadas ao comportamento entre as aplicações de recursos em ações socioambientais e o retorno financeiro das empresas, especificamente quando se considera um setor representativo do Índice Bovespa, como no caso, o setor de energia elétrica.

Este artigo compreende, além desta introdução, cinco outras seções: responsabilidade social, estudos empíricos internacionais e nacionais, notas metodológicas, discussão dos resultados e conclusão.

\section{REVISÃO DA LITERATURA}

A partir da década de 1960, estudos voltados ao desempenho socioambiental obtiveram destaques no meio acadêmico e diversas discussões foram fomentadas na busca por avaliar os possíveis benefícios econômico-financeiros que tais práticas poderiam proporcionar às empresas (RUFINO; MACHADO, 2016). O embate teórico sobre a relação positiva entre as práticas de responsabilidade socioambiental e o desempenho financeiro das empresas encontra sustentação na teoria dos shareholders e na teoria dos stakeholders, tendo em vista que cada grupo defende uma lógica, negando e incentivando as práticas de responsabilidade socioambiental (MACHADO et al., 2012).

Para Friedman (1970), na teoria dos shareholders, a única responsabilidade socioambiental da empresa é a geração de lucros e riqueza para seus acionistas, mantendo relação direta com o aumento do desempenho econômico-financeiro.
Já a teoria dos stakeholders pode ser entendida como uma teoria que preconiza a harmonia entre os objetivos empresariais e socioambientais de uma empresa (MACHADO et al., 2012). Reis, Matias e França (2013, p. 376) destacam que a teoria dos stakeholders une os objetivos empresariais aos socioambientais, uma vez que as organizações existem dentro de um ambiente socioambiental e, portanto, devem levar em consideração os problemas advindos desse ambiente.

\subsection{Responsabilidade socioambiental}

A temática responsabilidade socioambiental vem obtendo destaque no meio corporativo, principalmente em empresas com maior amplitude de visão, nas quais a missão não se restringe apenas na obtenção de resultados superavitários. No entanto, até este momento, inexiste um conceito plenamente aceito sobre responsabilidade social, que se confunde muitas vezes com "ações sociais", reduzindo seu escopo a atividades de cunho filantrópico. Esse reducionismo é inadequado e distorce a essência do que se espera de uma conduta socialmente responsável das empresas. Assim, embora a definição não seja unânime, tem-se que o termo responsabilidade social corporativa se refere, de forma ampla, a decisões de negócios tomadas com base em valores éticos que incorporam as dimensões legais e o respeito pelas pessoas, pelas comunidades e pelo meio ambiente (MACHADO FILHO, 2011).

O tema responsabilidade socioambiental se integra também ao tema da governança corporativa por meio do processo de gestão das relações contratuais e institucionais e do atendimento das demandas e dos interesses dos diversos participantes do meio em que a empresa está inserida. Tinoco e Kraemer (2004) destacam que a responsabilidade social consiste em gerar renda e emprego distribuídos de forma mais equitativa a todos os envolvidos, proporcionando aos que estão afastados de 
seus postos de trabalho e do mercado perspectivas de ingresso.

As iniciativas empresariais referentes à responsabilidade social podem ser observadas no balanço social, por meio da evidenciação das relações com os empregados, a sociedade e o meio ambiente. De origem europeia, o balanço social busca mostrar como foi originada a riqueza de uma empresa, sendo ainda peça integrante da contabilidade social, que é um ramo das ciências contábeis e tem como objetivo estudar os reflexos das variações patrimoniais nas empresas, na sociedade e no meio ambiente (KROETZ, 2000).

O balanço social é uma ferramenta de diagnóstico e gestão padronizada para a apresentação de indicadores de responsabilidade social, auxiliando nas iniciativas de interesse coletivo, tais como os projetos sociais, que visam à promoção da responsabilidade na comunidade nacional e global, dentre outros indicadores de desempenho da gestão, como investimentos, produtividade e geração de riqueza. Assim, o relatório deve apresentar informações sobre o histórico da empresa, seus princípios e valores, governança corporativa, perfil de empreendimento, diálogo com partes interessadas e indicadores de desempenho social, econômico e ambiental (REIS; MEDEIROS, 2007).

O balanço social é um instrumento de gestão e informação que visa evidenciar, de forma mais transparente possível, informações contábeis, econômicas, ambientais e sociais do desempenho das entidades aos diferentes usuários (TINOCO; KRAEMER, 2004). Dada a sua importância, algumas entidades propuseram modelos de balanços sociais, dentre os quais estão: o Global Reporting Initiative (GRI); o roteiro do Instituto Ethos; e o Instituto Brasileiro de Análises Sociais e Econômicas (Ibase). O GRI teve início em 1997, na Holanda, e utiliza um modelo de balanço social voltado à sustentabilidade econômica, social e ambiental, conferindo a ele a mesma utilidade e credibilidade dos relatórios financeiros. Trata-se de um acordo internacional, criado com uma visão de longo prazo, multistakeholder, cuja missão é elaborar e difundir diretrizes para a elaboração de relatórios de sustentabilidade aplicáveis global e voluntariamente pelas organizações (Ibidem, 2004).

O modelo de balanço social do Instituto Ethos foi desenvolvido a partir de estudos de benchmarking de diretrizes para relatórios no Brasil e no exterior, tomando por base a estrutura e o conteúdo de relatórios sociais propostos pela GRI, bem como a associação entre os indicadores Ethos de responsabilidade empresarial e o modelo de balanço social do Ibase (REIS; MEDEIROS, 2007). O modelo desenvolvido pelo Ibase mostra a evolução da empresa no contexto socioambiental envolvendo questões sobre educação, saúde, preservação do meio ambiente, valorização da diversidade, combate à fome, desenvolvimento de ações comunitárias, contribuições para aumento na qualidade de vida dos funcionários e criação de postos de trabalho (SCHEIBE; SOUTES, 2008).

Cumpre destacar que, em se tratando do setor de energia elétrica, o Manual de Contabilidade do Serviço Público de Energia Elétrica, instituído pela Agência Nacional de Energia Elétrica (Aneel), por intermédio da Resolução Aneel n. 444, de 26 de outubro de 2001, estabeleceu que as empresas outorgadas do setor devem apresentar o balanço social de acordo com os parâmetros contidos no modelo desenvolvido pelo Ibase. Ressalta-se ainda que, a partir do exercício de 2015, a Aneel tornou obrigatória a elaboração do Relatório de Responsabilidade Socioambiental e Econômico-Financeiro, que inclui o balanço social, estabelecendo um modelo básico de apresentação, ficando a critério da empresa elaborar seus relatórios com base em padrões mais abrangentes, como é o caso do modelo atualizado da GRI.

\subsection{Estudos empíricos internacionais e nacionais}

A academia tem mostrado interesse em pesquisas que associam responsabilidade socioambiental 
e desempenho financeiro de empresas (COCHRAN; WOOD, 1984; LIMA et al., 2013; MACHADO; MACHADO, 2009; MACHADO; MACHADO; SANTOS, 2010; MAHONEY; ROBERTS, 2007; MOSKOWITZ, 1972; NELLING; WEBB, 2009). Em termos de pesquisas internacionais, destaca-se o estudo pioneiro de Moskowitz (1972) ao postular que uma administração atenta e interessada socialmente obteria bom desempenho financeiro. No estudo de Moskowitz (1972), foram selecionadas 14 empresas credenciadas, com boa responsabilidade social, para as quais foi calculada uma taxa de retorno das ações ordinárias para os primeiros seis meses do ano de 1972. Os resultados mostraram que 14 ações haviam obtido média de 7,28\% de retorno, enquanto o maior índice de mercado, o Dow-Jones Industrials, apresentou resultado de 4,4\%, comprovando, assim, o argumento do autor.

Cochran e Wood (1984), com base na pesquisa de Moskowitz (1972), estudaram a relação entre os desempenhos social, ambiental e financeiro das empresas. Na pesquisa, foram ampliados os números de variáveis do estudo originário, cujos resultados indicaram relação negativa entre a idade dos ativos e a responsabilidade social. Mahoney e Roberts (2007) verificaram a relação entre o desempenho social, ambiental e financeiro de empresas canadenses. Usando dados em painel, os autores verificaram durante quatro anos uma significativa e positiva relação entre os desempenhos ambiental, social e financeiro das empresas, relatando que a responsabilidade social pode ser positivamente relacionada ao sucesso empresarial.

Nelling e Webb (2009) verificaram a relação causal entre responsabilidade social empresarial e desempenho financeiro. Por meio de uma amostra de mais de 600 empresas americanas entre 19932000, os autores utilizaram as variáveis retorno dos ativos e retorno de ações ordinárias como medida de mensuração do desempenho financeiro. Os resultados apresentaram evidencia de causalidade entre desempenho financeiro e responsabilidade social, denotando forte relação entre o retorno de ações e o investimento em responsabilidade social e ambiental. No entanto, a responsabilidade social e ambiental corporativa não influenciou o desempenho financeiro. Assim, concluiu-se que a responsabilidade social é mais influenciada pelas características não observáveis da empresa do que pelo retorno de seus ativos.

Com enfoque nas pesquisas nacionais, diversos autores (LIMA et al., 2013; MACHADO; MACHADO, 2009; MACHADO; MACHADO; SANTOS, 2009) vêm discutindo a relação entre responsabilidade social e as empresas. Machado e Machado (2009) investigaram a relação entre os indicadores sociais e o desempenho financeiro das empresas. Para atingir o objetivo da pesquisa, foram analisados, por meio de regressão linear múltipla, o desempenho financeiro e os indicadores sociais de 237 empresas pertencentes a 15 setores da economia num período de cinco anos. Os resultados da pesquisa sugerem a existência de uma relação positiva e significativa entre a responsabilidade social e o desempenho das empresas, no que tange aos indicadores internos e externos.

Machado, Machado e Santos (2010) verificaram se o volume de investimentos socioambientais efetuados pelas empresas difere entre setores. Para isso, utilizaram uma amostra de 212 empresas de nove setores da economia de 2005 a 2007. Os autores constataram a existência de uma diferença significativa entre investimentos sociais e ambientais de setores. Lima et al. (2013) investigaram o impacto dos investimentos socioambientais no desempenho financeiro das companhias do setor de energia elétrica em 2011. Com uma amostra composta por quarenta empresas e o emprego da técnica de regressão linear múltipla, os resultados encontrados indicam que os investimentos sociais internos influenciam positivamente os indicadores de desempenho. Os demais indicadores não apresentaram relação estatisticamente significativa. 
Como se observa, apesar da destacada importância dos mencionados estudos, seus resultados não se mostram conclusivos. Esta pesquisa, além de estudar um setor extremamente importante para a economia brasileira, difere-se dos estudos supramencionados por utilizar a técnica de regressão de dados em painel para analisar o impacto dos indicadores socioambientais no desempenho financeiro das empresas.

\subsection{O setor de energia elétrica brasileiro}

O setor de energia elétrica brasileiro é formado basicamente pela geração hidráulica (LEINIG et al., 2014) e, embora o desenvolvimento do setor tenha ocorrido pela alternância entre capital público e privado (SIFFERT FILHO et al., 2009), a partir da década de 1990, ocorreu um movimento de privatização de inúmeras empresas do setor. Atualmente, o setor de energia elétrica é dividido em três segmentos (geração, transmissão e distribuição), cuja exploração ocorre por empresas de capital público e/ou privado.

De acordo com Tolmasquim (2016), o sistema elétrico brasileiro (SEB) apresenta características singulares que balizam as decisões operacionais e de planejamento do setor, como: dimensões continentais; predominância de geração hidrelétrica; diversidade hidrológica das bacias hidrográficas; interligação plena entre as regiões a partir de um extenso sistema de linhas de transmissão.

Com relação à capacidade energética, destaca-se que o potencial hidráulico do país detém cerca de $10 \%$ do potencial hidráulico técnico mundial. De acordo com a Empresa de Pesquisa Energética (EPE), o setor de energia elétrica vem buscando de forma sistemática o tratamento dos aspectos socioambientais nos cenários de atuação e planejamento do setor (TOLMASQUIM, 2016).

Assim, apesar de o Brasil possuir uma matriz energética considerada limpa, com fontes de energia de biomassa, hidráulica, eólica, solar e nuclear, estas possuem um conjunto de fatores que potencialmente causam impactos ambientas negativos (BRAGA; FERREIRA, 2015) e exigem das empresas um planejamento e controle efetivo de ações que visem o cumprimento das obrigações legais para sua manutenção e a continuidade dos negócios.

\section{PERCURSO METODOLÓGICO}

Este estudo se caracteriza como uma pesquisa descritiva, pois reside na necessidade da coleta de dados em uma amostra de empresas para investigar a relação entre seus indicadores socioambientais e o desempenho empresarial. Para tanto, foram estudadas empresas brasileiras de capital aberto pertencentes ao setor de energia elétrica, de 2009 a 2015, totalizando sete anos. Trata-se de um estudo ex post facto, no qual o pesquisador não tem controle sobre as variáveis, no sentido de manipulá-las (COOPER; SCHINDLER, 2008).

Os procedimentos de pesquisa são bibliográficos e documentais. Os dados são coletados e tratados por meio de método quantitativo. A abordagem quantitativa é caracterizada pelo emprego da quantificação, tanto na coleta das informações como em seu tratamento, por meio de técnicas estatísticas. De acordo com Oliveira (1999), essa abordagem é muito utilizada em pesquisas de caráter descritivo que buscam investigar a relação entre as variáveis.

\subsection{Caracterização da amostra}

A seleção da amostra foi realizada de forma não probabilística e por conveniência. O conjunto de empresas elegidas está restrito às empresas brasileiras de capital aberto do setor de energia elétrica componentes do Índice Bovespa, que apresentam as informações necessárias para o cálculo dos indicadores socioambientais. A amostra final compreende nove empresas, conforme mostra o Quadro 1. 
Quadro 1 - Amostra da pesquisa

\begin{tabular}{|l|c|}
\hline Empresas & $\begin{array}{c}\text { Origem de } \\
\text { Capital }\end{array}$ \\
\hline Cemig Geração e Transmissão S.A. & Estatal \\
\hline Companhia Energética de São Paulo (Cesp) & Privada \\
\hline Companhia Paranaense de Energia (Copel) & Estatal \\
\hline CPFL Energia S.A. & Privada \\
\hline Centrais Elétricas Brasileiras S.A (Eletrobras) & Estatal \\
\hline $\begin{array}{l}\text { Eletropaulo Metropolitana -Eletricidade de } \\
\text { São Paulo }\end{array}$ & Privada \\
\hline Energias do Brasil (EDP) & Privada \\
\hline Light S.A. & Privada \\
\hline Tractebel Energia S.A. & Privada \\
\hline
\end{tabular}

Fonte: Elaboração dos autores (2016).

Como se observa, a maior parte das empresas selecionadas é caracterizada como privada (seis empresas). As empresas públicas são representadas por: Cemig, Copel e Eletrobras. Os dados foram coletados de duas formas distintas. Para a identificação dos dados socioambientais, as informações contidas nos balanços sociais foram utilizadas, as quais possibilitaram a construção das variáveis independentes. Para a obtenção das variáveis necessárias para o cálculo das métricas de desempenho financeiro e das variáveis de controle foram utilizadas as informações disponibilizadas no website da Bolsa de Valores de São Paulo (BM\&FBOVESPA). Após a obtenção das variáveis necessárias para os modelos estudados, duas modalidades de análise foram adotadas: análise descritiva e análise da regressão com dados em painel, com o auxílio dos softwares IBM SPSS Statistics 19.0 e Gretl 1.9.9.

\subsection{Hipóteses de teste da pesquisa}

A teoria dos stakeholders é sustentada pela premissa de que as organizações não servem apenas para maximizar os retornos dos acionistas, mas sim para atender a demandas de variados atores sociais, como: clientes, governo, acionistas, gestores, fornecedores, corpo funcional (FREEMAN, 1984). Sob a ótica da teoria dos stakeholders, a responsabilidade social corporativa (RSC) é vista como um compromisso que determinada organização assume com a sociedade (ASHLEY, 2005). Portanto, espera-se que as empresas que atendam esse compromisso apresentem resultados financeiros superiores. Baseando-se nessa premissa, foram testadas as seguintes hipóteses:

- $\mathbf{H}_{\mathbf{1}}$ : Os indicadores sociais internos (ISI) influenciam positivamente o desempenho financeiro das empresas.

- $\mathbf{H}_{2}$ : Os indicadores sociais externos (ISE) influenciam positivamente o desempenho financeiro das empresas.

- $\mathbf{H}_{3}$ : Os indicadores ambientais (IA) influenciam positivamente o desempenho financeiro das empresas.

\subsection{Variáveis e modelos da pesquisa}

Para mensurar o desempenho financeiro das empresas foram utilizadas separadamente como variáveis dependentes: return on assets (ROA, em português, retorno sobre ativos) e return on equity (ROE, em português, retorno sobre patrimônio líquido). Assaf Neto (2003) descreve que o ROA revela o retorno produzido pelo total de aplicações realizadas por uma empresa em seus ativos. O cálculo desse indicador utiliza o lucro líquido, como mostra a fórmula:

$$
\mathrm{ROA}=\frac{\mathrm{LL}}{\mathrm{AT}_{\mathrm{t}-1}}(1)
$$

Nota: ROA: retorno sobre ativos; $L \mathrm{~L}$ : lucro líquido; $\mathrm{AT}_{\mathrm{t}-1}$ : valor contábil médio dos ativos totais da empresa.

O índice do ROE mede a taxa de retorno para os acionistas. Os analistas de mercado de capitais, tanto quanto os acionistas, estão especialmente interessados neste índice. Em geral, quanto maior o retorno, mais atrativa é a ação (GROPELLI; NIKBAKHT, 1998). Dessa forma, o ROE representa o retorno obtido sobre o valor investido pelos sócios no empreendimento, ou seja, quanto os acionistas auferem de lucro para cada unidade monetária de 
recursos próprios. O papel deste índice é mostrar qual a taxa de rendimento do capital próprio, inclusive com o objetivo de comparar com a taxa de retorno de outros investimentos no mercado.

$$
\mathrm{ROE}=\frac{\mathrm{LL}}{\mathrm{PL}_{\mathrm{t}-1}}(2)
$$

Nota: ROE: retorno sobre patrimônio líquido; LL: lucro líquido; $\mathrm{PL}_{\mathrm{t}-1}$ : valor contábil médio do patrimônio líquido da empresa.

Como variáveis independentes, foram utilizados os indicadores socioambientais, obtidos por meio do balanço social: ISI, ISE e IA. O ISI representa todos os dispêndios financeiros que a empresa realiza internamente, como: encargos sociais, participação nos resultados, alimentação, saúde, capacitação etc. O ISE está associado a contribuições para a sociedade, representa investimentos perenes em programas sociais. Por fim, o IA representa os gastos da empresa com o meio ambiente (NOSSA et al., 2009). Nesta pesquisa, os gastos foram divididos pelos totais de ativos das empresas, para tornar mínimos os efeitos de escala.

Para explicar o desempenho das empresas, selecionou-se como variável de controle o tamanho da empresa (TAM). Para tanto, considerou-se o total do ativo da empresa no final de cada exercício. Para reduzir problemas estatísticos na amostra, foram extraídos os logaritmos naturais das variáveis. No Quadro 2, são apresentadas as variáveis utilizadas na pesquisa.

Os modelos utilizados na pesquisa descrevem a relação entre as proxies de desempenho financeiro e os indicadores socioambientais das empresas selecionadas, buscando investigar a existência de uma relação linear entre as variáveis.

$$
\begin{aligned}
& \mathrm{ROA}=\beta_{0}+\beta_{1} \text { ISI }+\beta_{2} \text { ISE }+\beta_{3} \mathrm{IA}+\beta_{4} \mathrm{TAM}+\varepsilon_{\text {it }} \text { (3) } \\
& \mathrm{ROE}=\beta_{0}+\beta_{1} \mathrm{ISI}+\beta_{2} \mathrm{ISE}+\beta_{3} \mathrm{IA}+\beta_{4} \mathrm{TAM}+\varepsilon_{\text {it }} \text { (4) }
\end{aligned}
$$

Nota: ROA: retorno sobre os ativos; ROE: retorno sobre o patrimônio líquido; ISI: indicador social interno; ISE: indicador social externo; IA: indicador ambiental; TAM: tamanho da empresa; $\varepsilon$ : erro residual.

Quadro 2 - Resumo das variáveis

\begin{tabular}{|l|l|l|l|}
\hline Nome da variável & Sigla & Classificação & Definição operacional \\
\hline Desempenho 1 & ROA & Dependente & Considera a razão entre o lucro líquido e o total de ativos da companhia \\
\hline Desempenho 2 & ROE & Dependente & $\begin{array}{l}\text { Obtido pela divisão entre o lucro líquido e o total de patrimônio líquido da } \\
\text { empresa }\end{array}$ \\
\hline $\begin{array}{l}\text { Indicador social } \\
\text { interno }\end{array}$ & ISI & Independente & $\begin{array}{l}\text { Representa a razão entre os investimentos internos da companhia em } \\
\text { participação nos resultados, alimentação, saúde, capacitação e seus totais de } \\
\text { ativos }\end{array}$ \\
\hline $\begin{array}{l}\text { Indicador social } \\
\text { externo }\end{array}$ & ISE & Independente & $\begin{array}{l}\text { Representa a razão entre os investimentos externos da companhia em } \\
\text { participação em ações sociais e os seus totais de ativos }\end{array}$ \\
\hline indicador ambiental & IA & Independente & $\begin{array}{l}\text { Representa a razão entre os investimentos ambientais da companhia e seus } \\
\text { totais de ativos }\end{array}$ \\
\hline Tamanho & TAM & Controle & \begin{tabular}{l} 
Representa os totais de ativos da empresa em cada período \\
\hline
\end{tabular} \\
\hline
\end{tabular}

Fonte: Elaboração dos autores (2016). 


\section{DISCUSSÃO E RESULTADOS}

Para a consecução do objetivo proposto, realizou-se inicialmente a análise descritiva dos dados, conforme dados mostrados na Tabela 1.

Os resultados obtidos mostram investimentos, em valores médios absolutos, de $\mathrm{R} \$ 696.050,62$, destinados pelas empresas a ações de bem-estar dos funcionários e suas famílias, bem como em programas de qualificação profissional. Os investimentos sociais externos representam os maiores montantes de aplicações de recursos, com média de $R \$ 3.880 .472,16$ por empresa, enquanto os investimentos ambientais correspondem a $\mathrm{R} \$ 120.165,95$.
A variável TAM, indicativa do tamanho das empresas, mostra valores médios em torno de $R \$$ 31 bilhões para os ativos. A empresa Eletrobras se destaca nesse ambiente, com montante aproximado de $R \$ 172$ bilhões. Em relação aos indicadores de desempenho financeiro, o retorno sobre os ativos alcança em média $5 \%$, enquanto o percentual de retorno sobre o PL representa $14 \%$. De forma geral, nota-se que, embora em valores absolutos os investimentos socioambientais sejam expressivos, o percentual diante do patrimônio das empresas se torna reduzido.

Destaca-se ainda que todas as variáveis apresentaram escores de Fator de Inflação de Variância entre 1 e 10, fornecendo indícios da inexistência de

Tabela 1 - Análise descritiva

\begin{tabular}{l|c|c|c|c|c}
\hline Variáveis & Média & Desvio padrão & Mínimo & Máximo & $\begin{array}{c}\text { Fator de Inflação } \\
\text { da Variância }\end{array}$ \\
\hline ROA & 0,05 & 0,05 & $-0,1$ & 0,17 & - \\
\hline ROE & 0,14 & 0,15 & $-0,36$ & 0,6 & - \\
\hline ISI & $696.050,62$ & $873.429,12$ & $73.211,00$ & $3.347 .420,00$ & 2,230 \\
\hline ISE & $3.880 .472,16$ & $2.758 .229,85$ & $35.808,00$ & $12.786 .533,00$ & 1,093 \\
\hline IA & $120.165,95$ & $113.419,38$ & $19.966,00$ & $521.948,00$ & 2,640 \\
\hline TAM ${ }^{*}$ & $31.280 .010,21$ & $43.154 .081,47$ & $9.421 .093,00$ & $172.195 .578,00$ & 1,385 \\
\hline
\end{tabular}

Nota: * Milhares de reais.

Fonte: Elaboração dos autores (2016).

Tabela 2 - Análise de correlação

\begin{tabular}{|c|c|c|c|c|c|c|c|}
\hline Variáveis & Testes & Ativo & ROA & ROE & ISI & ISE & IA \\
\hline \multirow{2}{*}{ TAM } & \begin{tabular}{|l|} 
Pearson \\
\end{tabular} & \multirow{2}{*}{1,000} & - & - & - & - & - \\
\hline & Spearman & & - & - & - & - & - \\
\hline \multirow{2}{*}{ ROA } & Pearson & $-0,577 * * *$ & \multirow{2}{*}{1,000} & - & - & - & - \\
\hline & Spearman & $-0,447 * * *$ & & - & - & - & - \\
\hline \multirow{2}{*}{ ROE } & Pearson & $-0,539 * * *$ & $0,970 * * *$ & \multirow{2}{*}{1,000} & - & - & - \\
\hline & Spearman & $-0,453^{* * *}$ & $0,961 * * *$ & & - & - & - \\
\hline \multirow{2}{*}{$|S|$} & Pearson & $-0,074$ & $0,232^{*}$ & $0,233^{*}$ & \multirow{2}{*}{1,000} & - & - \\
\hline & Spearman & 0,054 & 0,132 & 0,076 & & - & - \\
\hline \multirow{2}{*}{ ISE } & Pearson & $-0,122$ & $-0,219 *$ & $-0,172$ & 0,023 & \multirow{2}{*}{1,000} & - \\
\hline & Spearman & $-0,161$ & $-0,321 * *$ & $-0,227^{*}$ & 0,111 & & - \\
\hline \multirow{2}{*}{ IA } & Pearson & $-0,277 * *$ & 0,311 ** & $0,325 * * *$ & $0,683 * * *$ & 0,188 & \multirow{2}{*}{1,000} \\
\hline & Spearman & $-0,207$ & $0,320 * *$ & $0,333 * * *$ & $0,668 * * *$ & 0,227 * & \\
\hline
\end{tabular}

Nota: *Significativo ao nível de 10\%; **Significativo ao nível de 5\%; ***Significativo ao nível de $1 \%$

Fonte: Elaboração dos autores (2016). 
problema de colinearidade. Para reforçar esse pressuposto, foram utilizadas as técnicas de correlação de Pearson e Spearman, conforme a Tabela 2.

Na Tabela 2, observa-se a existência de uma relação negativa e significativa ( $p$-value $>0,01)$ entre as variáveis de desempenho (ROA e ROE) e o TAM, indicando, a priori, que quanto menor o valor dos ativos das empresas, melhores são seus retornos. Ressalta-se também a presença de relação negativa e significativa ( $p$-value>0,01) entre o TAM e o IA, sugerindo que empresas com maior volume de ativos tendem a realizar menores investimentos ambientais.
Com o propósito de analisar a relação dos indicadores socioambientais e o desempenho financeiro das empresas, realizou-se um estudo de dados em painel. Para a análise, adotou-se inicialmente o modelo Pooled (mínimos quadrados ordinários - MQO). Neste modelo, ISI, ISE e IA foram utilizados como variáveis explicativas, e os indicadores de rentabilidade, ROA e ROE, foram selecionados como variáveis dependentes. Com base nos resultados, foram realizados testes de diagnósticos de painel, observando o modelo que melhor explica o objetivo da pesquisa. Primeiramente, empregou-se o teste de Chow, que verifica se o modelo MQO

Tabela 3 - Modelo de efeitos fixos (ROA)

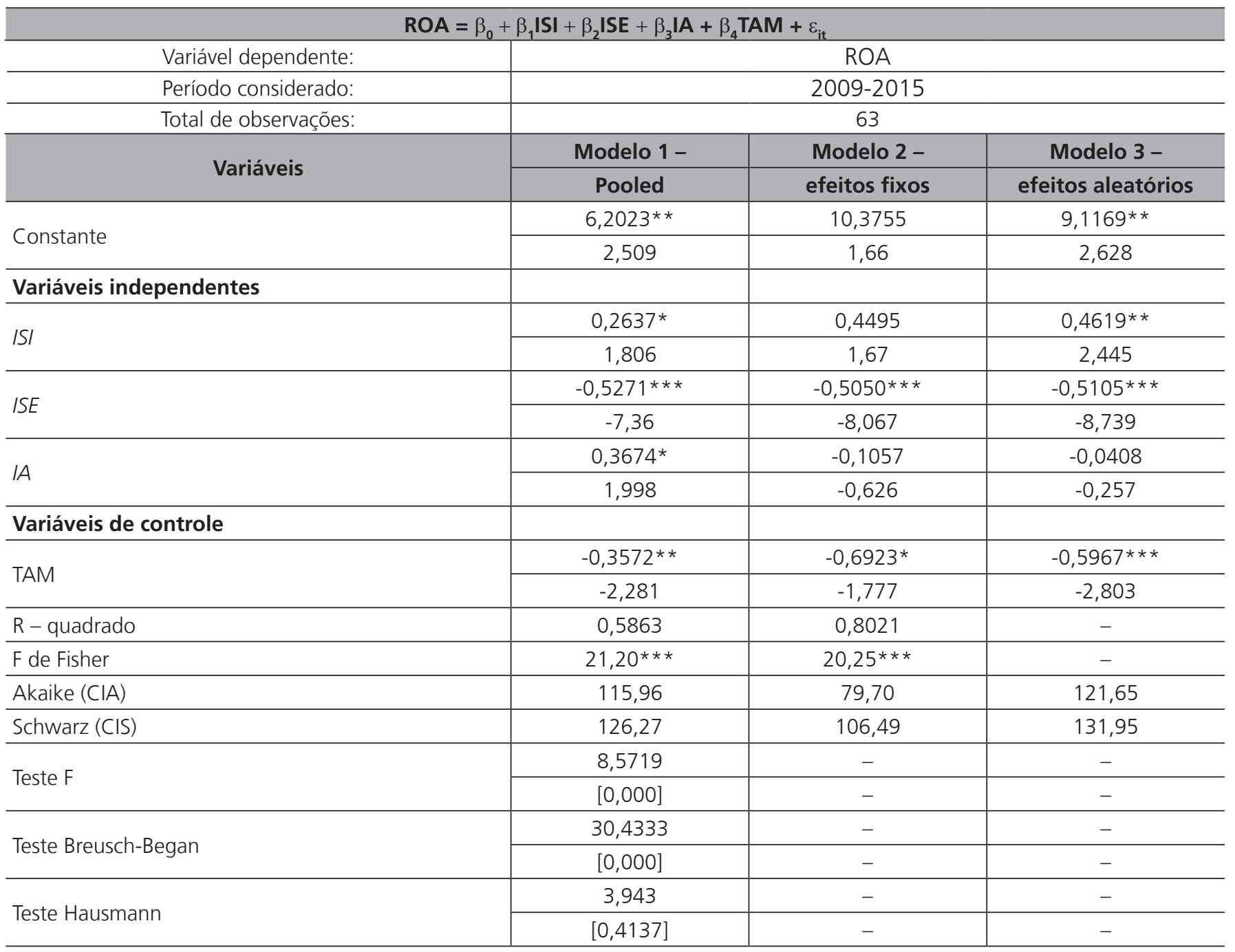

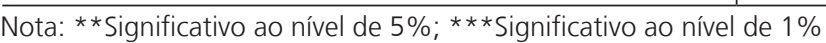

Fonte: Elaboração dos autores (2016). 
é mais adequado. Neste teste, a rejeição de $\mathrm{H}_{0}$ significa que o modelo de efeitos fixos é mais conveniente. O segundo teste utilizado foi o de BreuschPagan, em que a refutação de $\mathrm{H}_{0}$ confirma que o modelo de efeitos aleatórios é mais apropriado em relação ao modelo Pooled. Por fim, fez-se o uso do teste de Hausman para a opção entre efeitos fixos e efeitos aleatórios.

Conforme Gujarati e Porter (2011), a hipótese nula subjacente ao teste é que os estimadores do modelo de efeitos fixos e o de correção dos erros não diferem substancialmente. Assim, se a hipótese nula for rejeitada, denota-se que o modelo de efeitos aleatórios não é adequado, devido à inconsistência dos estimadores. Neste caso, é preferível o emprego do modelo por efeitos fixos. De acordo com os resultados obtidos para a variável dependente ROA, mostrados na Tabela 3, o modelo de efeitos aleatórios se mostra mais consistente para a análise.

A partir dos resultados do modelo de regressão, constatou-se que os investimentos sociais internos apresentam uma relação positiva e significativa $(B=0,4619 ; p<0,05)$ em relação ao retorno sobre os ativos. Esses resultados sugerem que investir nos funcionários reflete positivamente no desempenho da empresa. Assim, não foi rejeitada a $\mathrm{H}_{1}$ da pesquisa que afere que os ISI influenciam positivamente o desempenho financeiro das empresas.

Em relação aos investimentos sociais externos, averiguou-se a existência de uma relação negativa e significativa ( $B=-0,5105 ; p<0,01)$ com a primeira proxy de desempenho financeiro (ROA). Esse resultado sugere que as empresas tendem a apresentar retornos minimizados quando aplicam recursos em programa sociais, rejeitando, assim, a $\mathrm{H}_{2}$, que preconiza os ISE como influenciadores positivos no desempenho financeiro das empresas.

As empresas do setor de energia elétrica demonstraram relação negativa entre os investimentos ambientais e o ROA. Todavia, a ausência de significância estatística não permite confirmar tal achado. Com isso, para a variável ROA, rejeita-se $\mathrm{a}_{3}$, que sugere que os IA influenciam positivamente no desempenho financeiro. Destaca-se, ainda, que o TAM impacta negativamente o ROA, sugerindo que, em empresas menores, a relação entre os investimentos sociais e o desempenho financeiro é manifestada de forma mais perceptível.

A Tabela 4 mostra os resultados obtidos na regressão de dados em painel com efeitos fixos para a variável dependente ROE.

Como pode ser observado, a partir dos resultados de diagnóstico em painel para a variável dependente ROE, novamente o modelo de efeitos aleatórios se mostra com maior consistência. Assim como os resultados obtidos para o ROA, os achados iniciais indicam que os ISI apresentam uma relação positiva e significativa $(B=0,4359 ; p<0,05)$ com retorno sobre o PL. Esses resultados sugerem que os investimentos financeiros realizados nos funcionários impactam positivamente, melhorando, portanto, o retorno dos acionistas. Com isso, para ambas as variáveis, ROA e ROE, não é possível rejeitar a $H_{1}$ deste estudo.

Porém, os investimentos externos das empresas de energia elétrica tendem a minimizar significativamente os retornos sobre o capital próprio. Esses achados rejeitam a $\mathrm{H}_{2}$, e demonstram que gastos com investimentos sociais realizados pelas empresas com a sociedade reduzem o percentual de retorno aos investidores. Em relação aos investimentos ambientais, não foram identificadas relações significativas, rejeitando-se, portanto, $\mathrm{a}_{3}$ desta pesquisa.

O Quadro 3 apresenta os resultados dos testes de hipótese a respeito da influência dos indicadores socioambientais sobre o comportamento das variáveis relativas ao desempenho financeiro das empresas. 
Tabela 4 - Modelo de efeitos fixos (ROE)

\begin{tabular}{|c|c|c|c|}
\hline \multicolumn{4}{|c|}{ ROE $=\beta_{0}+\beta_{1}$ ISI $+\beta_{2}$ ISE $+\beta_{3}$ IA $+\beta_{4}$ TAM $+\varepsilon_{i t}$} \\
\hline Variável dependente: & & ROE & \\
\hline Período considerado: & & $2009-2015$ & \\
\hline Total de observações: & & 63 & \\
\hline \multirow{2}{*}{ Variáveis } & Modelo 1 - & Modelo 2 - & Modelo 3 - \\
\hline & Pooled & Efeitos fixos & Efeitos aleatórios \\
\hline \multirow{2}{*}{ Constante } & $6,7297 * *$ & 3,9365 & $8,1592 * *$ \\
\hline & 2,33 & 0,6388 & 2,116 \\
\hline \multicolumn{4}{|l|}{ Variáveis independentes } \\
\hline \multirow{2}{*}{ 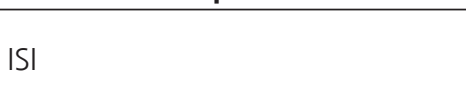 } & 0,107 & $0,5177^{*}$ & $0,4359 * *$ \\
\hline & 0,6271 & 1,951 & 2,14 \\
\hline \multirow{2}{*}{ ISE } & $-0,4730 * * *$ & $-0,4754 * * *$ & $-0,4646 * * *$ \\
\hline & $-5,653$ & $-7,703$ & $-7,8$ \\
\hline \multirow{2}{*}{ IA } & $0,6701 * * *$ & $-0,0784$ & 0,031 \\
\hline & 3,12 & $-0,4712$ & 0,1924 \\
\hline \multicolumn{4}{|l|}{ Variáveis de controle } \\
\hline \multirow{2}{*}{ TAM } & $-0,2942$ & $-0,2294$ & $-0,4756$ ** \\
\hline & $-1,608$ & $-0,5975$ & $-2,013$ \\
\hline$R$ - quadrado & 0,7372 & 0,8331 & - \\
\hline F de Fisher & $15,84^{* * *}$ & $24,71 * * *$ & - \\
\hline Akaike (CIA) & 134,00 & 78,06 & 143,64 \\
\hline Schwarz (CIS) & 144,30 & 104,84 & 153,94 \\
\hline \multirow{2}{*}{ Teste F } & 13,8206 & - & - \\
\hline & {$[0,000]$} & - & - \\
\hline \multirow{2}{*}{ Teste Breusch-Began } & 46,09 & - & - \\
\hline & {$[0,000]$} & - & - \\
\hline \multirow{2}{*}{ Teste Hausmann } & 6,9393 & - & - \\
\hline & {$[0,1391]$} & - & - \\
\hline
\end{tabular}

Nota: **Significativo ao nível de $5 \%$; ***Significativo ao nível de $1 \%$

Fonte: Elaboração dos autores (2016).

Quadro 3 - Resumo dos testes de hipóteses

\begin{tabular}{|c|c|c|c|}
\hline \multicolumn{2}{|c|}{ ROA } & \multicolumn{2}{|c|}{ ROE } \\
\hline $\mathrm{H}_{1}$ & Não rejeita & $\mathrm{H}_{1}$ & Não rejeita \\
\hline $\mathrm{H}_{2}$ & Rejeita & $\mathrm{H}_{2}$ & Rejeita \\
\hline $\mathrm{H}_{3}$ & Rejeita & $\mathrm{H}_{3}$ & Rejeita \\
\hline
\end{tabular}

Fonte: Elaboração dos autores (2016).

Como se observa, os achados da pesquisa não permitem rejeitar a $\mathrm{H}_{1}$ que preconiza que os ISI influenciam positivamente o desempenho financeiro das empresas. Todavia, as hipóteses $\mathrm{H}_{2}$ (os ISE influenciam positivamente o desempenho financeiro) e $\mathrm{H}_{3}$ (os IA influenciam positivamente $\mathrm{O}$ desempenho financeiro) foram rejeitadas, indicando que os investimentos em tais áreas não impactam positivamente no desempenho financeiro das companhias do segmento de energia elétrica.

\section{CONCLUSÃO}

O objetivo desta pesquisa consistiu em analisar a relação entre os indicadores socioambientais e o desempenho financeiro em companhias abertas do setor de energia elétrica que compõem o Índice Bovespa de 2009 a 2015. Os testes estatísticos 
mostram baixa multicolinearidade das variáveis exploratórias.

Para a análise de dados em painel, foram selecionadas como variáveis independentes: ISI, ISE e IA, tal como proposto pelo modelo Ibase. Como variável de controle, utilizou-se o TAM. Os indicadores ROA e ROE foram empregados como proxis do desempenho financeiro das empresas.

De acordo com os resultados obtidos na pesquisa, os indicadores ROA e ROE obtiveram resultados semelhantes quando comparados aos investimentos socioambientais e ao tamanho das empresas. Em síntese, os ISI apresentam uma relação direta e significativa com os resultados empresariais, indicando que os investimentos em funcionários retornam positivamente à empresa. No entanto, para os ISE essa relação é negativa, sugerindo que tais investimentos não proporcionam retornos em curto prazo. No que se refere aos investimentos ambientais, estes não influenciaram significativamente no resultado financeiro das empresas. Destaca-se ainda que o tamanho das empresas exerce influência sobre a relação entre os investimentos socioambientais e o desempenho financeiro empresarial, e estes resultados tendem a ser mais significativos em empresas com menores volumes de ativos.

Por fim, os resultados encontrados convergem parcialmente com os estudos de Machado e Machado (2009), no que se refere ao impacto positivo dos ISI no desempenho financeiro da empresa. Porém, divergem no que tange aos ISE, não havendo relação significativa. Cumpre destacar ainda que os resultados obtidos estão limitados às empresas brasileiras de capital aberto do setor de energia elétrica, pertencentes ao Índice Bovespa. As limitações estão relacionadas também aos indicadores selecionados e ao período amostral, bem como à exatidão das informações disponibilizadas pelo website da BM\&FBOVESPA. Como contribuição para trabalhos futuros, sugere-se a utilização de uma amostra maior de dados, a fim de buscar resultados mais robustos da relação entre os investimentos socioambientais e o desempenho financeiro das empresas.

\section{REFERÊNCIAS}

AlBERTON, A.; COSTA JUNIOR, N. C. A. Meio ambiente e desempenho econômico-financeiro: benefícios dos sistemas de gestão ambiental (SGAs) e o impacto da ISO 14001 nas empresas brasileiras. RAC-Eletrônica, Rio de Janeiro, v. 1, n. 2, p. 153-171, 2007. Disponível em: <http://bit.ly/2syRriB>. Acesso em: 10 jul. 2017.

ASHLEY, P. A. (Coord.). Ética e responsabilidade social nos negócios. 2. ed. São Paulo: Saraiva, 2005.

ASSAF NETO, A. Finanças corporativas e valor. São Paulo: Atlas, 2003.

BORBA, P. R. F. Relação entre desempenho social corporativo e de empresas no Brasil. In: ENCONTRO NACIONAL DA ANPAD, 30., 2006, Salvador. Anais...
Rio de Janeiro: Anpad, 2006. p. 1-17. Disponível em: <http://bit.ly/2sVEeQk>. Acesso em: 10 jul. 2017.

BRAGA, C.; FERREIRA, V. C. Os impactos ambientais no setor de energia elétrica brasileiro e a sua relação com o resultado líquido do exercício. In: CONGRESSO ANPCONT, 9., 2015, Curitiba. Anais... São Paulo: Anpcont, 2015. p. 1-15. Disponível em: <http://bit. ly/2ndEqvG >. Acesso em: 10 jul. 2017.

BRASIL. Agência Nacional de Energia Elétrica. Resolução n 444, de 26 de outubro de 2001. Institui o Manual de Contabilidade do Serviço Público de Energia Elétrica, englobando o Plano de Contas revisado, com instruções contábeis e roteiro para elaboração e divulgação de informações econômicas e financeiras. Diário Oficial da União, Brasília, DF, 29 out. 2001. 


\section{REFERÊNCIAS}

Disponível em: <http://bit.ly/2uG9abG>. Acesso em: 10 jul. 2017.

Manual de Contabilidade do Serviço Publico de Energia Elétrica. 2007. Disponível em: < www.aneel. gov.br/aplicacoes/leitura_arquivo/arquivos/manualjan-2007.pdf >. Acesso em: 10 jul. 2017.

Manual de Contabilidade do Setor Elétrico. 2015. Disponível em: < http://www2.aneel.gov.br/ arquivos/PDF/MCSE_-_Versao_2015.pdf >. Acesso em: 10 jul. 2017.

Ministério de Minas e Energia. 2015. Disponível em: < http://www.mme.gov.br/web/guest/pagina-inicial/ outras-noticas/-/asset_publisher/32hLrOzM KwWb/ content/capacidade-instalada-de-energia-eletrica-teveadicao-de-7-5-mil-mw-em-2014; jsessionid=CDA88A37 DB36846A8CE33B8CDED2F7D9.srv154 >. Acesso em: 10 jul. 2017.

BRITO, B. M. B. A reação do mercado acionário a eventos ambientais. 2005. 84 f. Dissertação (Mestrado em Administração) - Universidade Federal do Rio de Janeiro, Rio de Janeiro, 2005.

CALIXTO, L. Responsabilidade socioambiental: pública ou privada. In: ENCONTRO NACIONAL DA ANPAD, 31. 2007, Rio de Janeiro. Anais... Rio de Janeiro: Anpad, 2007. p. 1-16. Disponível em: <http://bit.ly/2tVCMl9>. Acesso em: 10 jul. 2017.

CAVALCANTI, J. M. M.; BOENTE, D. R. A relação de risco e retorno nas empresas integrantes do Índice de Sustentabilidade Empresarial no período de 2008 a 2010. Revista Ambiente Contábil, Natal, v. 4, n. 1, p. 5171, 2012.

COCHRAN, P. L.; WOOD, R. A. Corporate social responsibility and financial performance. Academy of
Management Journal, Briarcliff Manor, v. 27, n. 1, p. 4256, 1984.

COOPER, D. R.; SCHINDLER, P. S. Métodos de pesquisa em administração. 7. ed. Porto Alegre: Bookman, 2008.

CRISÓSTOMO, V. L.; FREIRE, F. S.; VASCONCELLOS, F. C. Corporate social responsibility, firm value and financial performance in Brazil. Social Responsibility Journal, Bingley, v. 7, n. 2, p. 295-309, 2011.

FREEMAN, R. E. Strategic management: A stakeholder approach. Boston, MA: Pitman, 1984.

FRIEDMAN, M. The social responsibility of business is increase its profits. New York Times Magazine, New York, n. 33, p. 122-126, 1970.

GROPPELLI, A. A.; NIKBAKHT, E. Administração financeira. São Paulo: Saraiva, 1998.

GUJARATI, D. N.; PORTER, D. C. Econometria básica. 5. ed. Porto Alegre: McGraw-Hill, 2011.

HOLANDA, A. P. et al. O desempenho socioambiental nas empresas do setor elétrico brasileiro: uma questão relevante para o desempenho financeiro? Revista de Gestão Social e Ambiental, São Paulo, v. 5, n. 3, p. 5372, 2011.

KLASSEN, R. D.; MCLAUGHLIN, C. P. The impact of environmental management on firm performance. Management Science, Catonsville, v. 42, n. 8, p. 11991214, 1996.

KROETZ, C. E. S. Balanço social: teoria e prática. São Paulo: Atlas, 2000.

LEINIG, A. K. G. et al. Electronic reverse auction: an analysis of its use in public administrations of cities in 


\section{REFERÊNCIAS}

Brazil. Australian Journal of Basic and Applied Sciences, Ammān, v. 8, p. 274-281, 2014.

LIMA, A. A. P. et al. Investimentos socioambientais e o desempenho econômico-financeiro das empresas: estudo empírico nas companhias abertas listadas na BM\&FBovespa do setor de energia elétrica. In: CONGRESSO BRASILEIRO DE CUSTOS, 20. 2013, Uberlândia. Anais... São Leopoldo: Associação Brasileira de Custos, 2013. p. 1-16.

MACHADO FILHO, C. P. Responsabilidade social e governança: o debate e as implicações. São Paulo: Cengage Learning, 2011.

MACHADO, M. A. V. et al. Análise da relação entre investimentos socioambientais e a inclusão de empresas no Índice de Sustentabilidade Empresarial - (ISE) da BM\&FBovespa. Revista de Ciências da Administração, Florianópolis, v. 14, n. 32, p. 141-156, 2012.

MACHADO, M. A. V.; MACHADO, M. R. Responsabilidade social impacta o desempenho financeiro das empresas? In: CONGRESSO USP DE CONTROLADORIA E CONTABILIDADE, 6., 2009, São Paulo. Anais... São Paulo: Fipecafi, 2009. p. 1-15. Disponível em: <http:// bit.ly/2tzpQ2t>. Acesso em: 10 jul. 2017.

MACHADO, M. R.; MACHADO, M. A. V.; SANTOS, A. A relação entre setor econômico e investimentos sociais e ambientais. In: CONGRESSO USP DE CONTROLADORIA E CONTABILIDADE, 7., 2010, São Paulo. Anais... São Paulo: Fipecafi, 2010. p. 1-16. Disponível em: <http:// bit.ly/2vq1BXr>. Acesso em: 10 jul. 2017.

MAHONEY, L.; ROBERTS, R. W. Corporate social performance, financial performance and institutional ownership in Canadian firms. Accounting Forum, Amsterdam, v. 31, n. 3, p. 233-253, 2007.
MOORE, G. Corporate social and financial performance: an investigation in the U.K. supermarket industry. Journal of Business Ethics, New York, v. 34, n. 3-4, p. 299-315, 2001.

MOSKOWITZ, M. R. Choosing socially responsible stocks. Business and Society Review, Hoboken, v. 1, p. 71-75, 1972.

NELLING, E.; WEBB, E. Corporate social responsibility and financial performance: the "virtuous circle" revisited. Review of Quantitative Finance and Accounting, New York, v. 32, n. 2, p. 197-209, 2009.

NOSSA, V. et al. A Relação entre o retorno anormal e a responsabilidade social e ambiental: um estudo empírico na Bovespa no período de 1999 a 2006. Brazilian Business Review, Vitória, v. 6, n. 2, maio/ago. 2009.

OLIVEIRA, S. L. Tratado de metodologia científica: projetos de pesquisas, TGI, TCC, monografias, dissertações e teses. 2. ed. São Paulo: Pioneira Thomson Learning, 1999.

PERRINI, F. et al. Deconstructing the relationship between corporate social and financial performance. Journal of Business Ethics, New York, v. 102, n. 1, p. 59-76, 2011. Suplemento 1.

PRESTON, L. E.; O'BANNON, D. P. The corporate socialfinancial performance relationship: a typology and analysis. Business \& Society, Thousand Oaks, v. 36, n. 4, p. 419-429, 1997.

REIS, C. N.; MEDEIROS, L. E. Responsabilidade social das empresas e balanço social: meios propulsores do desenvolvimento econômico e social. São Paulo: Atlas, 2007.

REIS, E. M.; MATIAS, M. A.; FRANÇA, R. S. Investimento em meio ambiente e o desempenho econômico das 


\section{REFERÊNCIAS}

empresas aderidas ao Índice Carbono Eficiente - ICO2. Revista de Educação e Pesquisa em Contabilidade (REPeC), Brasília, DF, v. 7, n. 4, p. 372-386, 2013.

ROSSI JÚNIOR, J. L. What is the value of corporate social responsibility? An answer from Brazilian sustainability index. Journal of International Business and Economics, Madison, v. 9, p. 169-178. 2009.

RUFINO, M. A.; MACHADO, M. R. Relação entre desempenho socioambiental e econômico-financeiro: um estudo em periódicos nacionais. Revista Uniabeu, Belford Roxo, v. 9, n. 22, p. 161-176, 2016.

SCHEIBE, M. L.; SOUTES, D. O. Responsabilidade social: um estudo de caso em uma cooperativa paranaense. In: CONGRESSO USP DE CONTROLADORIA E CONTABILIDADE, 5., 2008, São Paulo. Anais... São Paulo: Fipecafi, 2008. p. 1-15. Disponível em: <http:// bit.ly/2wmGh2j>. Acesso em: 10 jul. 2017.

SILVA, E. C. Contabilidade empresarial para gestão de negócios: guia de orientação fácil e objetivo para apoio e consulta de executivos. São Paulo: Atlas, 2008.
SIFFERT FILHO, N. F. et al. O papel do BNDES na expansão do setor elétrico nacional e o mecanismo de project finance. BNDES Setorial, Rio de Janeiro, n. 29, p. 3-36, 2009.

STEGER, U. Building a business case - general findings, observations and lessons learned. In: STEGER, U. (Org.). The business case of sustainability: building industry cases for corporate sustainability. London, MacMillan, 2004, p. 1-72.

TINOCO, J. E. P.; KRAEMER, M. E. P. Contabilidade e gestão ambiental. São Paulo: Atlas, 2004.

TOLMASQUIM, M. T. (Coord.). Energia renovável: hidráulica, biomassa, eólica, solar, oceânica. Rio de Janeiro: EPE, 2016.

WAJNBERG, D. Sustentabilidade nos bancos brasileiros: exame da divulgação do relacionamento entre iniciativas socioambientais e o desempenho financeiro corporativo. 2008. 67 f. Dissertação (Mestrado em Administração) Universidade Federal do Rio de Janeiro, Rio de Janeiro, 2008. 